\title{
Non-disease specific patient-reported outcome measures of health-related quality of life in juvenile idiopathic arthritis: a systematic review of current research and practice
}

\author{
Justyna Młyńczyk ${ }^{1}$ (D) Paweł Abramowicz ${ }^{1}$ D $\cdot$ Maciej K. Stawicki ${ }^{1}$ (D) - Jerzy Konstantynowicz ${ }^{1}$ (D)
}

Received: 2 November 2021 / Accepted: 20 December 2021 / Published online: 31 December 2021

(c) The Author(s) 2021

\begin{abstract}
Juvenile idiopathic arthritis (JIA), as a chronic condition, is associated with symptoms negatively impacting health-related quality of life (HRQL). Regarding growing interest in the implementation of the patient-reported outcome measures (PROMs), we aimed to review the non-disease specific PROMs addressing HRQL assessment, potentially useful in the clinical care of JIA and daily practice. A systematic literature search was conducted using MEDLINE/PubMed, Google Scholar, Scopus and Embase databases (1990 to 2021), with a focus on the recent 5-years period. Entry keywords included the terms: "children", "adolescents", "JIA", "chronic diseases", "HRQL", "PROMs" and wordings for the specific tools. Several available PROMs intended to measure HRQL, non-specific to JIA, were identified. The presented outcomes differed in psychometric properties, yet all were feasible in assessing HRQL in healthy children and those with chronic diseases. Both EQ-5D-Y and PedsQL have already been tested in JIA, showing relevant reliability, validity, and similar efficiency as disease-specific measurements. For PROMIS ${ }^{\circledR}$ PGH-7 and PGH-7 +2, such validation and cross-cultural adaptation need to be performed. Considering the future directions in pediatric rheumatology, the large-scale implementation of PROMIS ${ }^{\circledR}$ PGH-7 and PGH-7 + 2 in JIA offers a particularly valuable opportunity. The PROMs reflect the patient perception of the chronic disease and allow to understand child's opinions. The PROMs may provide an important element of the holistic medical care of patients with JIA and a standardized tool for clinical outcomes, monitoring disease severity and response to treatment.
\end{abstract}

Keywords Juvenile arthritis · Health-related quality of life · Patient-reported outcome measures $\cdot$ Children

$\begin{array}{ll}\text { Abbreviations } \\ \text { EQ-5D } & \text { EuroQol } \\ \text { HRQL } & \text { Health-related quality of life } \\ \text { JIA } & \text { Juvenile idiopathic arthritis } \\ \text { PedsQL } & \text { Pediatric quality of life inventory } \\ \text { PGH } & \text { Pediatric global health } \\ \text { PROMIS } & \begin{array}{l}\text { Patient-reported outcomes measurement infor- } \\ \text { mation system }\end{array} \\ \text { PROMs } & \text { Patient-reported outcome measures } \\ \text { QoL } & \text { Quality of life }\end{array}$

Jerzy Konstantynowicz jurekonstant@o2.pl

1 Department of Pediatrics, Rheumatology, Immunology, and Metabolic Bone Diseases, University Children's Hospital, Medical University of Bialystok, Waszyngtona Street 17, 15-274 Bialystok, Poland

\section{Introduction}

In the past decades, the Quality of Life (QoL) has become a significant objective of medical research and an important component of public health. Furthermore, the patient perspective has gained a new role in contemporary health care worldwide, particularly regarding chronic diseases. The meaning and perception of QoL can be interpreted in various ways [1], nonetheless, according to the World Health Organization guidelines, QoL is defined as ,,an individual's perception of their position in life in the context of the culture and value systems in which they live and in relation to their goals, expectations, standards and concerns" [2].

A more specific term, health-related quality of life (HRQL), reflects the correlation between health and functioning of an individual [3]. HRQL outcomes are recognized as a credible rating of subjective health of adults [4], as well as that of children and adolescents [5]. Even though the understanding and interpretation of HRQL vary between 
individuals, causing thereby the assessment of the outcome a great challenge, some influential organizations like the National Institute for Health and Care Excellence (NICE) recommend $\mathrm{HRQL}$ measurements in clinical care and trials $[6,7]$.

One of the newly implemented methods allowing evaluation of HRQL are patient-reported outcome measures (PROMs). An increasing interest in using PROMs in clinical practice has been noted [8] whereas the PROMs have been shown as an important element of different areas of healthcare [9]. The PROMs are able to measure "patient's health status that comes directly from the patient, without the interpretation of the patient's responses", according to the current definition [10], and provide the patient's perspective and information that can only be given by patient himself [11]. So the core element is the direct and reliable response. They comprise a possibility to expand knowledge about patient's functioning, identify problems affecting patient, improve treatment and care, and allow to construct health-care responsive to the patient $[1,12]$. Importantly, PROMs may also be useful to indicate the correlation between healthcare interventions and patients' HRQL [13].

HRQL is qualified as a crucial outcome of chronic health conditions [14, 15], e.g. diabetes, asthma, juvenile arthritis, and its improvement should be one of the main goals of patient care [16]. It is well known that chronic conditions predispose to lower HRQL, however, not only disease symptoms per se may implicate reduced HRQL, the duration of the disease is also relevant [17]. Other factors impacting HRQL are e.g. socioeconomic status, psychosocial behavior and support, and health behaviors [18]. In view of the abovementioned factors, subjective psychical or mental health complaints among patients with chronic conditions can result in deterioration of HRQL and should be definitely taken into consideration in patient care $[19,20]$.

Juvenile Idiopathic Arthritis (JIA) is one of the most prevalent chronic conditions of childhood, with the prevalence of 1 per 1,000 children, moreover, it is the most common pediatric rheumatic disease [21]. According to the classification criteria, JIA includes seven subtypes stratified by the number of involved joints, presence of systemic features, and additional markers as rheumatoid factor (RF) [22]. The subsets of JIA differ regarding the clinical picture, and also pathogenic background, i.e. etiopathogenesis and genetics, yet so all of them contribute to the development of disability and deterioration of HRQL to a great extent [23, 24].

A core feature of JIA is the inflammation of joints such as knees, ankles, hands, elbows, and/or wrists. Symptoms include swelling, pain, stiffness, and limited function of joints [25], with pain being the most commonly observed and disturbing ailment [26]. It is documented that children with a prolonged course of the disease may have modified pain sensitivity and perception [27], and reduced physical activity due to functional impairment [28, 29]. JIA can proceed also with extra-articular manifestations, e.g. fevers, erythematous rash, hepatosplenomegaly, enlarged lymph nodes, serositis, enthesitis [30] and not to mention uveitis, the most widely appearing extra-articular sign of JIA, potentially leading to vision loss [31]. Patients with JIA may experience deterioration of emotional and psychosocial functioning, given that anxiety and depressive symptoms are related to pain and decreased mobility [32]. Furthermore, JIA, as a chronic condition, is linked to increased use of healthcare services, taking into account frequent hospitalizations [33]. In summary, children and adolescents with JIA are at a higher risk of a lower HRQL due to the chronic nature of the disease, limited mobility, and the symptoms listed above [34].

Regarding the importance of HRQL assessment in the clinical care of patients with chronic diseases, implementation of HRQL, especially patient-reported, outcomes should be discussed more extensively [35]. In this report, we presented several currently available PROMs addressing HRQL measurements, which could be useful and may be potentially included in daily practice in JIA. We focused on the JIA-non-specific outcomes, given that HRQL JIA- specific measurements, e.g. JAMAR [36] or JAQQ [37] are commonly known and accepted. The state of the art suggests that development of the new methods allowing to assess of HRQL data from a child's level in this condition is particularly needed.

\section{Methods and search strategy}

We conducted a systematic literature search using Medline (via PubMed), Google Scholar, Scopus, and Embase electronic databases (through 1990 to 2021), focusing on the last 5-years period. Based on the MeSH thesaurus, we used entry key words for "children", "adolescents", "JIA", "chronic diseases", "HRQL", "PROMs" and the available eligible names of the instruments applicable for its assessment. The search was limited to English-language articles, both systematic reviews, and original papers. All abstracts were examined, followed subsequently by full-text analysis and review, resulting in evaluation of univocity and trustworthiness of the study. Study protocol, including literature references search, article collection, eligibility, data extraction, and subsequent review and discussion, was based on current recommendations [38-40]. A total of 2412 published records were screened and, following standardized search process, finally 41 articles were included in the review (Fig. 1).

After comprising a list of HRQL outcome measures, we selected several for further and a more detailed review, all of them eventually permitting to obtain patient-reported data. 
Fig. 1 Flow diagram of database searching

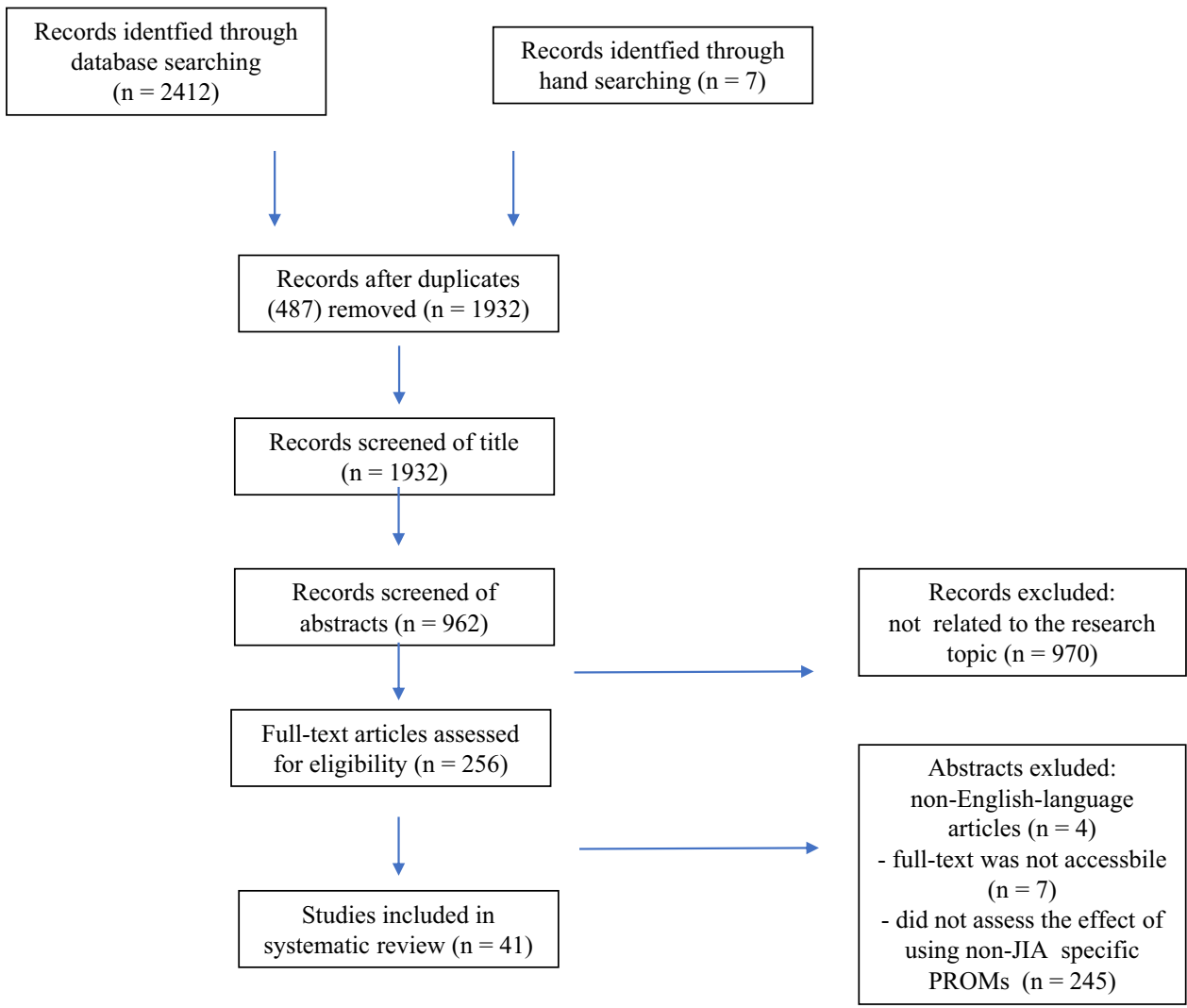

We presented current information on the use of the measures: reliability, validity, practical applications, and psychometric properties. The summarized comparative data were presented in Table 1.

\section{Results}

\section{EuroQoL (EQ-5D)}

\section{Content}

The EuroQol's EQ-5D standardized non-disease specific instruments were developed in 1990 to delineate and evaluate health-related quality of life [41]. The EuroQol measurements produce a generic cardinal index of health, aiming to assess the physical, mental, and social functioning of an individual [42], and are today widely recommended by several health technology assessment agencies for use in the cost-utility analysis [43].

Standard EQ-5D construction consists of a descriptive system questionnaire of five dimensions: 1- mobility, 2- selfcare, 3- usual activities, 4- pain/discomfort and 5- anxiety/ depression called EQ-SD self-classifier, and an EQ-VAS (visual analog system) vertical scale rating current health status with the endpoints 100 at the top of the scale and 0 at the bottom [44]. The EQ-5D instruments occur in two basic forms, the EQ-5D-3L version with three levels of severity in each of the five dimensions, and the EQ-5D-5Lversion with five levels of severity in each of the five dimensions [45]. Besides the increased number of severity levels the EQ5D-5L form differs from the EQ-5D-3L in the changed label of the most severe option regarding the mobility dimension [Supplementary material].

In 2009, the EuroQol Group implemented the EQ-5D-Y, based on the EQ-5D-3L self- completed instrument suitable for children and adolescents. The EQ-5D-Y, as other EQ-5D measurements, contains the EQ-5D descriptive system questionnaire and the EQ-VAS. The EQ-5D-Y's descriptive system is composed of five dimensions, listed as 1- mobility (walking about), 2- looking after myself, 3- doing usual activities (for example going to school, hobbies, sports, playing, doing things with family or friends), 4- having pain or discomfort and 5- feeling worried, sad or unhappy. As can be seen above, the headers of the dimensions were specified and adapted obviously to younger respondents to refine the comprehension of the text. Each of the five dimensions has assigned three levels of severity, referring to the present health state (TODAY) [46]. In contrast to the adult version EQ-5D-3L, the EQ-5D-Y has modified labeling of the most severe option in all of the dimensions, also the wording of the mildest option was transformed in the looking after myself dimension [Supplementary material]. In this article the EQ-5D-Y (with three levels of severity) has been 


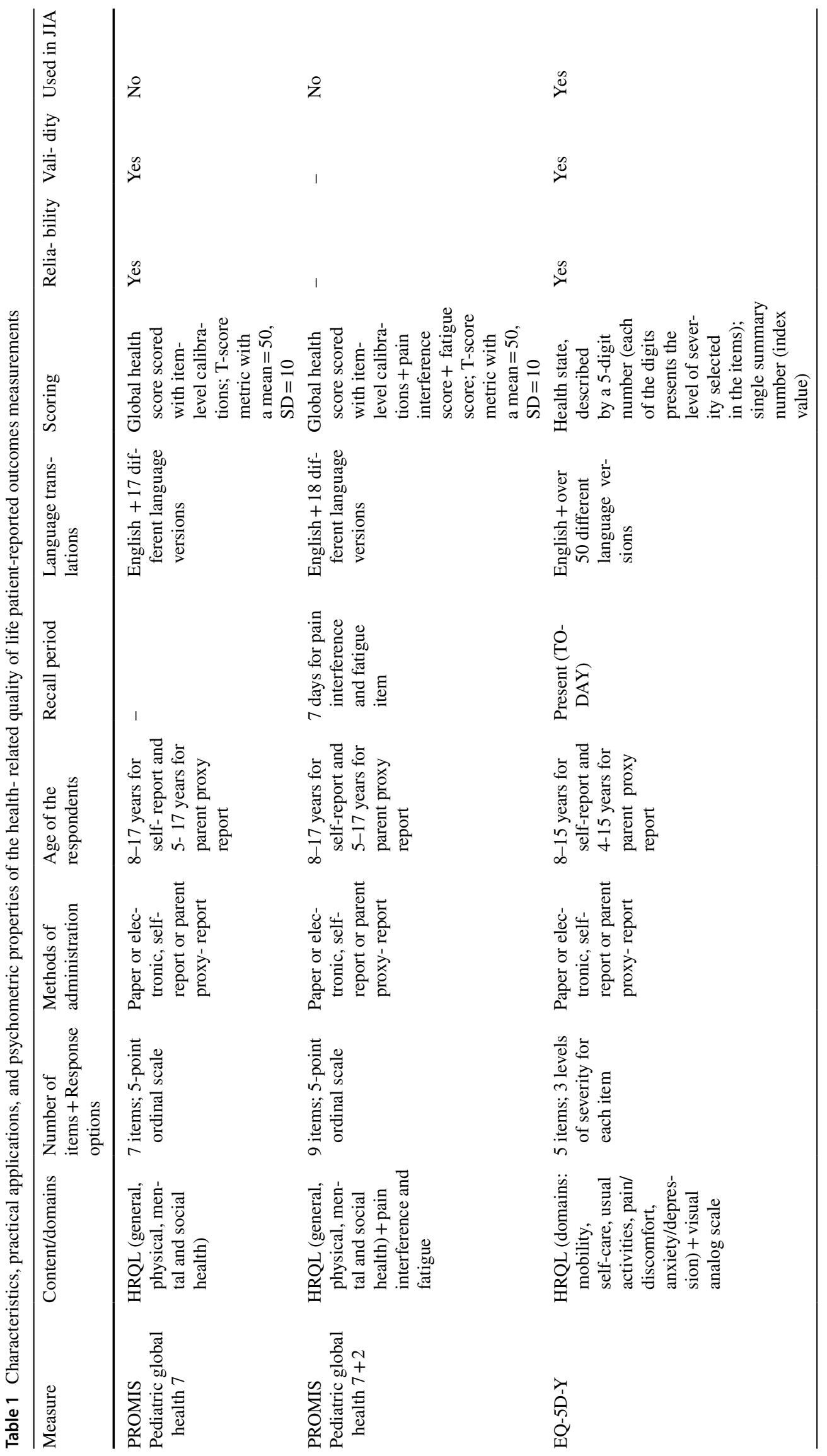




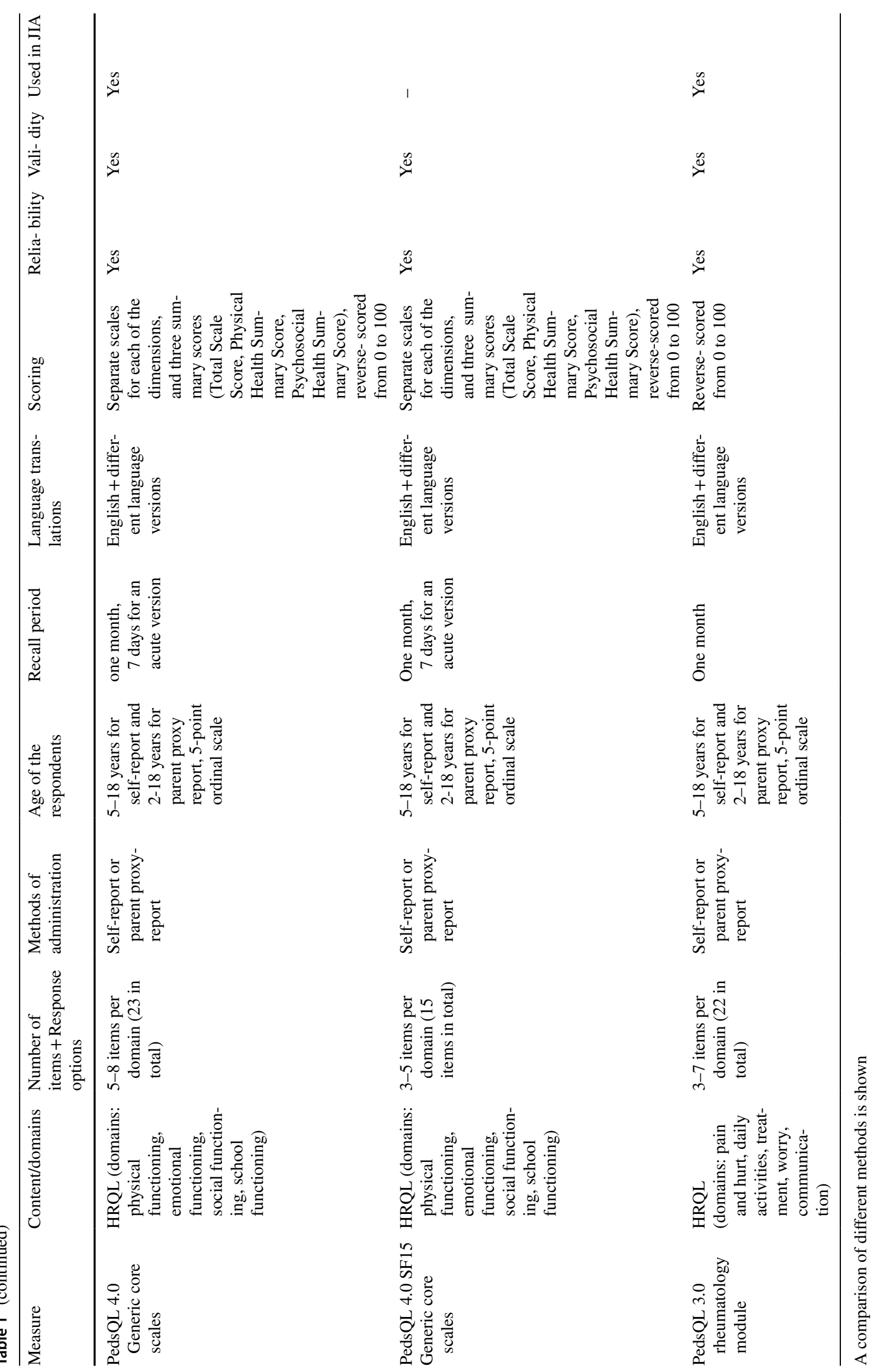


detailed but, noticeably, a new version of the instrument with five severity levels, the EQ-5D-Y-5L, is under development [47-49]. The second component of the instrument, the EQ-5D-Y VAS, preserves standard vertical construction. Instructions for the EQ-VAS were considerably simplified and clarified to reassure a more child-friendly and appropriate approach.

\section{Practical application}

The EQ-5D-Y assessment is designed to be used for children and adolescents aged 8-15 years. For older children, 16-year-old and above, adult versions of EQ-5D instruments are usually recommended, while for children younger than 8 years (4-7 years), a parent proxy-reported measurement should rather be used. There are two proxy versions available: version 1, in which the caregiver rates the child's HRQL in their (proxy's) opinion, and version 2, in which the caregiver is asked to rate the HRQL from a child's position (how a child would rate his/her HRQL). The EQ-5D-Y is obtainable in various formats (paper and digital on PDAs/ smartphones/tablets/computers) and a number of translations (currently more than 50 self-complete language versions).

\section{Scoring}

The aim of the EQ-5D-Y is to indicate the respondent's health state, numerically described by a 5 -digit code. This 5-digit code emerges from combining 1-digit numbers corresponding to the level of severity selected in every dimension of the descriptive system questionnaire. In conclusion, there is a possibility to define in total 243 diverse health states. The health status can also be presented as a single summary number (index value) reflecting the qualitative assessment of health in compliance with the preferences of the general population of a given country/region (value sets). Index values facilitate calculating quality-adjusted life years (QALYs), which can be particularly useful in the cost-utility analysis [50].

\section{Psychometric properties}

The EQ-5D-Y's feasibility, reliability, and validity were legitimated in the research conducted on German, Italian, South African, Spanish, and Swedish children and adolescents. The reported agreement in test-retest reliability ranged between 69.8 and $99.7 \%$, with Kappa coefficients about 0.67 . Validity was established by comparing children with a previously foreseen disparity in HRQL [51]. According to a study conducted on a representative sample of Canadian children, also the VAS-based index demonstrated logical consistency, with no statistically important disparity between the actual and predicted VAS values [52].
The instrument has been implemented in several welldesigned studies of chronic conditions, e.g. asthma [53], diabetes type 1 [54-56], and JIA. Findings from a study conducted on 219 English-speaking children aged 8-15 years revealed that the EQ-5D-Y was valid in the determination of HRQL among pediatric patients with JIA. Moreover, the report demonstrated this generic instrument had similar efficiency as disease- specific measurements, contributing to a more productive JIA management [57].

\section{Pediatric quality of life inventory (PedsQL)}

\section{Content}

The PedsQL, designed in 1999 by Varni et al., is a standardized generic instrument to measure HRQL in the pediatric population [58]. More specifically, this modular measurement system consists of the generic core scales and complementing them disease-specific modules, allowing assessment of HRQL across a broad spectrum of pediatric populations, including healthy children and those with chronic conditions. In 2002, the PedsQL 3.0 Rheumatology Module was developed, encompassing a specific module with a great scope of HRQL assessment across various dermatological conditions, connective tissue diseases, and musculoskeletal diseases [59].

The PedsQL 4.0 Generic Core Scales, self and parent proxy reported, in versions for children aged 5-18 years contain 23 items related to four major dimensions:1- physical functioning (8 items), 2- emotional functioning (5 items), 3 - social functioning ( 5 items), and 4 - school functioning (5 items), with suitable response options ranging from 0 (never) to 4 (almost always). In a self-reported version for younger children (5-7 years), a simplified, graphically shown as a happy-to-sad face 3-point scale is used. The parent proxy report for toddlers aged 2-4 years includes 21 items in the same four, listed above, dimensions. This form differs by limiting to 3 items in the school functioning dimension.

The PedsQL 4.0 Generic Core Scales are also available in shorter simplified forms: The PedsQL 4.0 SF15 Generic Core Scales, composed of 15 items derived from the original measurements. For all of the age-specific versions, the PedsQL SF15 comprises the same four dimensions followed by the same response options as in the original measurements.

The PedsQL 3.0 Rheumatology Module in versions (self and parent proxy reported) for children aged 8-18 years is composed of five dimensions containing 22 items in total, as listed: 1- pain and hurt (4 items), 2 - daily activities (5 items), 3 - treatment (7 items), 4- worry (3 items), 5-communication (3 items). Response options are 5-point scaled from 0 (never) to 4 (almost always). Both self and parent proxy reports for children aged 5-7 years comprise 20 items in the same five dimensions. Response options in the self-report 
are the same as in the age-adjusted PedsQL 4.0 Generic Core Scales version i.e. graphically shown 3-point scale. The parent proxy report for toddlers aged 2-4 years describes three dimensions: 1-pain and hurt (4 items), 2-daily activities (5 items), and 3-treatment (5 items).

The PedsQL 4.0 Generic Core Scales and the PedsQL SF15 are offered in a variant with a 1-month recall period, and in an acute variant with a recall period lasting 7 days. Such methodological flexibility may be useful in adjustment for disease or treatment duration. All of the PedsQL 3.0 Rheumatology Module versions are designed to achieve a one-month recall period.

\section{Practical application}

The PedsQL measurements are available in numerous language translations and can be administered as both self and parent proxy report in versions categorized as for younger children aged 5-7, children aged 8-12, adolescents aged 13-18 years, and as a parent proxy report for toddlers aged 2-4 years. The method is based on paper format, however, for the PedsQL 4.0 Generic Core Scales self-report for adolescents a convenient e-version is also accessible.

\section{Scoring}

The PedsQL 4.0 Generic Core Scales generate four allencompassing scales, one for each of the dimensions, and three summary scores 1- Total Scale Score (23 items), 2- Physical Health Summary Score (8 items), and 3- Psychosocial Health Summary Score (15 items). The PedsQL SF15 produces, respectively four scales, one for each of the dimensions, and three summary scores 1-Total Scale Score (15 items), 2-Physical Health Summary Score (5 items), and 3-Psychosocial Health Summary Score (10 items). The measurements, containing the PedsQL 3.0 Rheumatology Module, using this method are reverse-scored and linearly transformed from 0 to $100(0=100$ to $4=0)$, according to the following pattern: the higher the scores the better HRQL.

\section{Psychometric properties}

All of the methods, including the PedsQL 4.0 Generic Core Scales, the PedsQL 4.0 SF15 Generic Core Scales, and the PedsQL 3.0 Rheumatology Module have proven good reliability and validity. A study conducted on 963 pediatric patients and 1,629 parents, indicated internal consistency reliability for the Total Scale Score of the PedsQL 4.0 Generic Core Scales with Cronbach's alpha values rated on 0.88 for a child self, and 0.90 for parent proxy report. The validity was demonstrated using the known-groups method and showed that this instrument differentiated healthy subjects from patients with acute or chronic diseases [60]. The Total Score, Physical Health Summary Score, and Psychosocial Health Summary Score from the PedsQL 4.0 SF15 were adequately reliable for all age group comparisons, with alpha coefficient $>$ or $=0.70$, as reported by Chan et al. The PedsQL 4.0 SF15 distinguished between children varying in health status [61]. The PedsQL 3.0 Rheumatology Module's reliability, validity, and usefulness were also demonstrated elsewhere, based on a study of 231 children and 244 parents, followed in the pediatric rheumatology clinic. The investigators showed again excellent reliability for age group comparisons in which Cronbach's alpha ranged from 0.75 to 0.86 for a child self-report, and from 0.82 to 0.91 for a parent proxy report. Validity was appointed by comparing groups of children with different clinical status (the known-groups method) and resulted in sufficient quality [59].

The PedsQL 4.0 Generic Core Scales and the PedsQL 3.0 Rheumatology Module have already been used in JIA [62-64], and also in other rheumatic diseases like lupus erythematosus [65] or fibromyalgia [66].

\section{Patient-reported outcomes measurement information system ${ }^{\circledast}$ (PROMIS ${ }^{\circledast}$ ): a new possibility}

\section{Content}

The US National Institutes of Health (NIH) PatientReported Outcomes Measurement Information System ${ }^{\circledR}$ (PROMIS $®$ ) was designed to evolve standardized instruments (short forms, item banks, computer adaptive tests (CATs) measuring multiple domains of physical, mental, and social health in children and adults [67-69]. The measurements are not disease-specific and allow assessment across many chronic conditions, treatment settings, and the general population [70].

The Pediatric Global Health (PGH-7) measure and its extended version $(\mathrm{PGH}-7+2)$ are dedicated to HRQL assessment in children. The PGH-7 comprises a sevenitem brief summary of a child's general, physical, mental, and social health. To each of the items belong five response options. The first four items' response options correspond to grading scores of 5 down to 1 , respectively. The fifth, sixth, and seventh items' response options score through 5 to 1 for item number five and from 1 up to 5 for items number six and seven, respectively.

The extended version of the Pediatric Global Health $(\mathrm{PGH}-7+2)$ has incorporated two calibrated items from PROMIS ${ }^{\circledR}$ pediatric and parent proxy item banks to evaluate fatigue and pain interference, with response options scored from 1 up to 5 , respectively [Supplementary material]. The recall period for these two items is 7 days. 


\section{Practical application}

Both PGH-7 and PGH-7 +2 can be administered as a patient self-report for children aged 8-17 years or as a parent proxy report for children aged 5-17 years. Both measures are fixed length short forms obtainable in paper/hard copy as well as in electronic formats on platforms for computer administration - Assessment Center API (including REDCap) and Epic PROMIS CAT Application. The PGH-7 has been affordable in 18 different language versions and the PGH-7 +2 in 19 so far, whereas further consecutive translations are in preparation.

\section{Scoring}

The PGH-7 and the PGH-7 +2 are able to generate global health scores, additionally, the PGH- $7+2$ produces separate scores for pain interference and fatigue item. These two scores do not contribute to the global health score and are qualified as a preliminary estimate for pain interference and fatigue. Both measurements, as all of the PROMIS ${ }^{\circledR}$ domains, are scored with item-level calibrations based on Item Response Theory (IRT) - a group of statistical models. The IRT scores are transformed to the T-score metric and reported with a mean of 50 and a standard deviation of 10. The most accurate implementation of the scoring is the usage of the Health Measures Scoring Service or an electronic data collection tool, e.g. Assessment Center, REDCap auto-score. If such proceeding is not possible, the tables converting raw scores into $\mathrm{T}$-score metric values are to be applied.

\section{Psychometric properties}

The PGH-7 measure's internal consistency alpha coefficient was rated on 0.88 for the child self-report form and 0.84 for the parent proxy report form, as identified in the developmental study of 3635 children aged 8-17 years and 1,807 parents of children aged 5-17 years, conducted among US population. Both self and parent proxy reports showed excellent test- retest reliability. There was no invariance in item functioning by age, gender, race, or ethnicity. Furthermore, the study's findings proved that the PGH-7 items were well understood by children from the age of 8 years upwards [71]. Another study on a group of 4636 American 8-17-yearsold children and their 2609 parents showed convergent and discriminant validity of both the PGH-7 self-reported and parent proxy versions with PROMIS pediatric measures of physical, mental, and social health. Children with chronic conditions, Hispanic ethnicity, and those with low socioeconomic status generated lower scores of the PGH-7 measurement [72].
Moreover, the PGH-7 measure has already been trialed in several chronic conditions among the pediatric population, e.g. asthma [73], diabetes type 1, inflammatory bowel disease, cystic fibrosis [74, 75], celiac disease [76], nephrotic syndrome [77], cerebral palsy [78], and Down syndrome [79], not to mention recent attempts of evaluation of COVID-19 pandemic's impact on the mental and social health of children and adolescents [80, 81]. Among asthmatic patients, the PGH-7 measure's reliability based on Cronbach's alpha oscillated from 0.66 to 0.81 for child self-report, and from 0.76 to 0.82 for parent proxy report. Patients with well- controlled asthma had PGH-7 scores higher than patients who were uncontrolled, with a conclusion that the PGH-7 was a reliable and valid assessment of general health status among children with asthma [73].

At the moment, numerous of the pediatric measures, e.g. anger, anxiety, depressive symptoms, fatigue, mobility, pain interference, pain behavior and peer relationships, have already been tested in JIA [35], still yet, the PGH-7 and the PGH-7 +2 have not been successfully utilized in this disease. As so the PGH-7 has the potential to be a useful clinical and research tool assessing children's self or parent proxy reported global health status and quality of life, future research should focus on the implementation of this measure just in JIA.

\section{Discussion}

This review described several currently available PROMs intended to measure HRQL, non-specific to JIA. PROMs are foreseen to be the future of healthcare management for both the adults and children [82], however, using PROMs in clinical care in children leads to some challenges. Principally, a disturbing issue is the construction of mentally- and age-adapted contents and formats [83, 84]. Nevertheless, it is proven that children from seven years of age, and sometimes younger, are capable of understanding and reporting to PROMs [85]. For younger children, or those unable to respond according to the health conditions, parental proxy reports are available as well. Still yet, as shown in the literature on pediatric health outcomes, compatibility between parent proxy and self-reports of HRQL may considerably differ. Results of parent proxy HRQL measurements are different depending on the methodology and instrument used [86]. Moreover, there is a tendency of parents of children with chronic diseases to evaluate their children's HRQL as much poorer than it would be noted from the child's perspective itself [87]. Thus, both the parent proxy and child self-reported outcomes have their pros and cons, still yet, whenever a child can respectively respond, the child's selfreport should always become an overall objective [88]. 
The majority of the presented PROMs are feasible in assessing HRQL in the pediatric population, both healthy children and those with chronic inflammatory diseases. However, all of the instruments differ in their properties and have specific limitations. One of the disparities between the instruments is score development. The PROMIS $®$ PGH-7 and the EQ-5D-Y are unidimensional, generating one general health score/state. The PedsQL 4.0 Generic Core Scales and the PedsQL 3.0 Rheumatology Module are regarded as multidimensional, producing scales, one for each of the dimensions [Table 1]. At this point, there is a need to highlight that contrastingly to other abovementioned PROMs, the PedsQL instruments include disease-specific modules complementary to the general HRQL assessment, what constitutes an advantage in the care of chronically ill children, and allow to more precisely and adequately measure HRQL.

As reported elsewhere, self-evaluated patient's HRQL state can importantly vary from the patient's HRQL state reported by others [89], especially in the comparison of assessment conducted by an adult and by a child. The HRQL instruments should have child self- and parent proxy reports calibrated and validated separately, and, as proven, this requirement is fulfilled by the majority of the described PROMs - the PROMIS ${ }^{\circledR}$ PGH-7, the PedsQL 4.0 Generic Core Scales, the PedsQL 4.0 SF15 Generic Core Scales, the PedsQL 3.0 Rheumatology Module and the EQ-5D-Y. Still yet, the usage of the EQ-5D-Y meets an opportunity of the insufficient number of the specific child and adolescents value sets, as the great number of presently available value sets are based on the adult population [46].

Currently, the golden standard in disease-specific HRQL assessment in JIA is the Juvenile Arthritis Multidimensional Assessment Report (JAMAR), which consists of 15 dimensions combining general (physical function, pain-VAS scale, HRQL, overall well-being- VAS scale) and disease-specific outcomes (number of inflammated joints, morning stiffness, extra-articular symptoms, disease activity-VAS scale, actual disease status, disease course, treatment and its side effects). HRQL outcome includes two subscales, the Physical Health (5 items) and the Psychosocial Health (5 items), allowing total and separate scoring for both subscales. Both self- and parent proxy reports are accessible [36, 90].

The JAMAR gives a full view on both patient's health status and course of the disease and is recommended to use whenever disease's impact on the child's well-being should be precisely rated, e.g. relapse, exacerbation [57]. The PedsQL 3.0 Rheumatology Module was created to complement the general HRQL assessment and may be insufficient to substitute disease-specific PROMs in such cases. However, when the disease-specific outcomes are not essentially needed, presented PROMs could be a better option. The EQ-5D-Y, the PedsQL 4.0 Generic Core Scales and the PedsQL 4.0 SF15 Generic Core Scales are more complex in the matter of dimensions and contained therein items, what can result in more comprehensive HRQL assessment. What is more, the EQ-5D-Y, and both the PedsQL 4.0 Generic Core Scales and the PedsQL3.0 Rheumatology Module, have already been tested in JIA, still yet, such validation and cross-cultural adaptation research need to be performed with the use of PROMIS ${ }^{\circledR}$ PGH-7 and PGH-7 + 2 measurements.

The PROMIS ${ }^{\circledR}$ PGH-7 and PGH-7 + 2 seem to be particularly promising in the healthcare of JIA patients, due to their properties, briefness (7/9 items) and connected with these procedures time-effectiveness, various forms of comfortable electronic administration, facile scoring, general availability, and optional integration with other PROMIS ${ }^{\circledR}$ pediatric measurements. By implication, this specific tool means an inevitable opportunity for future directions in JIA $[45,71]$.

\section{Conclusion}

Using the HRQL questionnaires in pediatric rheumatology is evidently below expectations. This may be due to limited awareness of health care professionals, whereas attitudes of physicians towards patient perspectives seem to be underachieved. The PROMs reflect most accurately patient perception of the disease and are valuable components of the holistic medical care, although the evaluation methods used may be time-consuming and challenging while interpretation in children may implicate difficulties [83, 84]. Therefore, these methods have not yet been brought into general use, and have been underrated. The child's voice and opinions, in particular those based on the PROMs, play an important role and may offer an interesting opportunity to extend practical knowledge, leading thereby to the improvement of long-term rheumatologic care and the patient-physician relationship. Even if the implementation of PROMs in routine check-ups is difficult on a regular basis, these methods would add practical value and would benefit the appropriate management of JIA [89]. In conclusion, the PROMs may provide a standardized tool for a better insight into the psychosocial nature of the chronic pediatric disease, and for understanding possible poor clinical outcomes, monitoring disease severity, and response to treatment.

Supplementary Information The online version contains supplementary material available at https://doi.org/10.1007/s00296-021-05077-x.

Author contributions JM, PA, and JK made substantial contributions to study design and conception, JM performed the literature search, JM, PA and MKS were responsible for data collection, acquisition, and analysis, JM, PA and JK were involved in the interpretation of the material, JM wrote the first draft of the paper. JK and PA were responsible for critical revision of the manuscript. All authors contributed to the discussion, read and approved the final version of the manuscript. 
Funding This research was supported by $\mathrm{PhD}$ School from the Medical University of Bialystok, Poland.

Availability of data and materials The raw data supporting the conclusions of this article will be made available by the authors, without undue reservation, the medical history of the patients.

\section{Declarations}

Conflict of interest The authors declare that the research was conducted in the absence of any commercial or financial relationships that could be construed as a potential conflict of interest.

Ethical approval This work did not require the approval of the bioethics committee.

Open Access This article is licensed under a Creative Commons Attribution 4.0 International License, which permits use, sharing, adaptation, distribution and reproduction in any medium or format, as long as you give appropriate credit to the original author(s) and the source, provide a link to the Creative Commons licence, and indicate if changes were made. The images or other third party material in this article are included in the article's Creative Commons licence, unless indicated otherwise in a credit line to the material. If material is not included in the article's Creative Commons licence and your intended use is not permitted by statutory regulation or exceeds the permitted use, you will need to obtain permission directly from the copyright holder. To view a copy of this licence, visit http://creativecommons.org/licenses/by/4.0/.

\section{References}

1. Haraldstad K, Wahl A, Andenæs R et al (2019) A systematic review of quality of life research in medicine and health sciences. Qual Life Res 28(10):2641-2650. https://doi.org/10.1007/ s11136-019-02214-9

2. WHOQOL Group (1995) The World Health Organization quality of life assessment (WHOQOL): position paper from the World Health Organization. Soc Sci Med 41(10):1403-1409. https://doi. org/10.1016/0277-9536(95)00112-K

3. Ow N, Mayo NE (2020) Health-related quality of life scores of typically developing children and adolescents around the world: a meta-analysis with meta-regression. Qual Life Res 29(9):23112332. https://doi.org/10.1007/s11136-020-02519-0

4. Romero M, Vivas-Consuelo D, Alvis-Guzman N (2013) Is health related quality of life (HRQoL) a valid indicator for health systems evaluation? Springerplus 2(1):664. https://doi.org/10.1186/ 2193-1801-2-664

5. Rajmil L, Roizen M, Psy AU et al (2012) Health-related quality of life measurement in children and adolescents in Ibero-American countries, 2000 to 2010. Value Health 15(2):312-322. https://doi. org/10.1016/j.jval.2011.11.028

6. Andrees V, Westenhöfer J, Blome C et al (2019) Towards patients' understanding of health-related quality of life-a mixedmethod study in psoriasis and multiple sclerosis. Qual Life Res 28(10):2717-2729. https://doi.org/10.1007/s11136-019-02227-4

7. (2013) Guide to the methods of technology appraisal (PMG9) Nice.org.uk. 2021 https://www.nice.org.uk/process/pmg9/chapt er/foreword. Accessed 29 Oct 2021

8. Roe D, Mazor Y, Gelkopf M (2019) Patient-reported outcome measurements (PROMs) and provider assessment in mental health: a systematic review of the context of implementation. Int J Qual Health Care. https://doi.org/10.1093/intqhe/mzz084

9. Holmes MM, Lewith G, Newell D et al (2017) The impact of patient-reported outcome measures in clinical practice for pain: a systematic review. Qual Life Res 26(2):245-257. https://doi.org/ 10.1007/s11136-016-1449-5

10. U.S. Department of Health and Human Services FDA Center for Drug Evaluation and Research, U.S. Department of Health and Human Services FDA Center for Biologics Evaluation and Research, U.S. Department of Health and Human Services FDA Center for Devices and Radiological Health (2006) Guidance for industry: patient-reported outcome measures: use in medical product development to support labeling claims: draft guidance. Health Qual Life Outcomes 4(1):79. https://doi.org/10.1186/ 1477-7525-4-79

11. Tzelepis F, Sanson-Fisher R, Zucca A, Fradgley E (2015) Measuring the quality of patient-centered care: why patient-reported measures are critical to reliable assessment. Patient Prefer Adherence 9:831-835. https://doi.org/10.2147/PPA.S81975

12. Øvretveit J, Zubkoff L, Nelson EC et al (2017) Using patientreported outcome measurement to improve patient care. Int $\mathrm{J}$ Qual Health Care 29(6):874-879. https://doi.org/10.1093/intqhe/ mzx 108

13. Fleischmann M, Vaughan B (2019) Commentary: statistical significance and clinical significance-a call to consider patient reported outcome measures, effect size, confidence interval and minimal clinically important difference (MCID). J Bodyw Mov Ther 23(4):690-694. https://doi.org/10.1016/j.jbmt.2019.02.009

14. Puka K, Conway L, Smith ML (2020) Quality of life of children and families. Handb Clin Neurol 174:379-388. https://doi.org/10. 1016/B978-0-444-64148-9.00028-4

15. Leclair V, Regardt M, Wojcik S, Hudson M (2016) Health-related quality of life (HRQoL) in idiopathic inflammatory myopathy: a systematic review. PLoS ONE 11(8):e0160753. https://doi.org/10. 1371/journal.pone.0160753

16. Fischer KI, Barthel D, Otto C et al (2019) Minimal associations between clinical data and children's self-reported health-related quality of life in children with chronic conditions-a cross-sectional study. Front Pediatr 7:17. https://doi.org/10.3389/fped.2019.00017

17. Barthel D, Ravens-Sieberer U, Nolte S et al (2018) Predictors of health-related quality of life in chronically ill children and adolescents over time. J Psychosom Res 109:63-70. https://doi.org/ 10.1016/j.jpsychores.2018.03.005

18. Gomes AC, Rebelo MAB, de Queiroz AC et al (2020) Socioeconomic status, social support, oral health beliefs, psychosocial factors, health behaviours and health-related quality of life in adolescents. Qual Life Res 29(1):141-151. https://doi.org/10.1007/ s11136-019-02279-6

19. Silva N, Pereira M, Otto C et al (2019) Do 8- to 18-year-old children/adolescents with chronic physical health conditions have worse health-related quality of life than their healthy peers? A meta-analysis of studies using the KIDSCREEN questionnaires. Qual Life Res 28(7):1725-1750. https://doi.org/10.1007/ s11136-019-02189-7

20. Otto C, Barthel D, Klasen F et al (2018) Predictors of self-reported health-related quality of life according to the EQ-5D-Y in chronically ill children and adolescents with asthma, diabetes, and juvenile arthritis: longitudinal results. Qual Life Res 27(4):879-890. https://doi.org/10.1007/s11136-017-1753-8

21. Okamoto N, Yokota S, Takei S et al (2019) Clinical practice guidance for juvenile idiopathic arthritis (JIA) 2018. Mod Rheumatol 29(1):41-59. https://doi.org/10.1080/14397595.2018.1514724

22. Ringold S, Angeles-Han ST, Beukelman T et al (2019) 2019 American college of rheumatology/arthritis foundation guideline for the treatment of juvenile idiopathic arthritis: therapeutic approaches for non- systemic polyarthritis, sacroiliitis, and 
enthesitis. Arthritis Care Res (Hoboken) 71(6):717-734. https:// doi.org/10.1002/acr.23870

23. Cimaz R, Marino A, Martini A (2017) How I treat juvenile idiopathic arthritis: a state of the art review. Autoimmun Rev 16(10):1008-1015. https://doi.org/10.1016/j.autrev.2017.07.014

24. Castillo-Vilella M, Giménez N, Tandaipan JL et al (2021) Clinical remission and subsequent relapse in patients with juvenile idiopathic arthritis: predictive factors according to therapeutic approach. Pediatr Rheumatol Online J 19(1):130. https://doi.org/ 10.1186/s12969-021-00607-0

25. Petty RE, Southwood TR, Manners P et al (2004) International league of associations for rheumatology. International league of associations for rheumatology classification of juvenile idiopathic arthritis: second revision, Edmonton, 2001. J Rheumatol 31(2):390-392

26. Lalloo C, Mesaroli G, Makkar M, Stinson J (2020) Outcome measures for pediatric pain: practical guidance on clinical use in juvenile arthritis. Arthritis Care Res (Hoboken) 72(S10):358-368. https://doi.org/10.1002/acr.24217

27. Arnstad ED, Rypdal V, Peltoniemi S et al (2019) Early selfreported pain in juvenile idiopathic arthritis as related to longterm outcomes: results from the Nordic juvenile idiopathic arthritis cohort study. Arthritis Care Res (Hoboken) 71(7):961-969. https://doi.org/10.1002/acr.23715

28. Nørgaard M, Herlin T (2019) Specific sports habits, leisure- time physical activity, and school- educational physical activity in children with juvenile idiopathic arthritis: patterns and barriers. Arthritis Care Res (Hoboken) 71(2):271-280. https://doi.org/10. 1002/acr.23795

29. Sherman G, Nemet D, Moshe V et al (2018) Disease activity, overweight, physical activity and screen time in a cohort of patients with juvenile idiopathic arthritis. Clin Exp Rheumatol 36(6):1110-1116

30. Martini A, Ravelli A, Avcin T et al (2019) Toward new classification criteria for juvenile idiopathic arthritis: first steps, Pediatric Rheumatology International Trials Organization international consensus. J Rheumatol 46(2):190-197. https://doi.org/10.3899/ jrheum. 180168

31. Sestan M, Grguric D, Sedmak M et al (2020) Quality of life in children suffering from juvenile idiopathic arthritis-associated uveitis. Rheumatol Int 40(7):1117-1121. https://doi.org/10.1007/ s00296-020-04536-1

32. Hanns L, Radziszewska A, Suffield L et al (2020) Association of anxiety with pain and disability but not with increased measures of inflammation in adolescent patients with juvenile idiopathic arthritis. Arthritis Care Res (Hoboken) 72(9):1266-1274. https:// doi.org/10.1002/acr.24006

33. Bele S, Mohamed B, Chugh A et al (2019) Impact of using patient-reported outcome measures in routine clinical care of paediatric patients with chronic conditions: a systematic review protocol. BMJ Open 9(3):e027354. https://doi.org/10.1136/bmjop en-2018-027354

34. Doeleman MJH, de Roock S, Buijsse N et al (2021) Monitoring patients with juvenile idiopathic arthritis using health-related quality of life. Pediatr Rheumatol Online J 19(1):40. https://doi. org/10.1186/s12969-021-00527-z

35. Morgan EM, Carle AC (2020) Measures of health status and quality of life in juvenile idiopathic arthritis. Arthritis Care Res (Hoboken) 72(S10):565-576. https://doi.org/10.1002/acr.24372

36. Filocamo G, Consolaro A, Schiappapietra B et al (2011) A new approach to clinical care of juvenile idiopathic arthritis: the juvenile arthritis multidimensional assessment report. J Rheumatol 38(5):938-953. https://doi.org/10.3899/jrheum.100930

37. Duffy CM, Arsenault L, Duffy KN et al (1997) The juvenile arthritis quality of life questionnaire-development of a new responsive index for juvenile rheumatoid arthritis and juvenile spondyloarthritides. J Rheumatol 24(4):738-746

38. Gupta S, Rajiah P, Middlebrooks EH et al (2018) Systematic review of the literature: best practices. Acad Radiol 25(11):14811490. https://doi.org/10.1016/j.acra.2018.04.025

39. Harris JD, Quatman CE, Manring MM et al (2014) How to write a systematic review. Am J Sports Med 42(11):2761-2768. https:// doi.org/10.1177/0363546513497567

40. Liberati A, Altman DG, Tetzlaff J et al (2009) The PRISMA statement for reporting systematic reviews and meta-analysis of studies that evaluate health care interventions: explanation and elaboration. PLoS Med 6(7):1-28. https://doi.org/10.1371/journal.pmed. 1000100

41. EuroQol Group (1990) EuroQol-a new facility for the measurement of health-related quality of life. Health Policy 16(3):199_ 208. https://doi.org/10.1016/0168-8510(90)90421-9

42. Brooks R (1996) EuroQol: the current state of play. Health Policy 37(1):53-72. https://doi.org/10.1016/0168-8510(96)00822-6

43. Kennedy-Martin M, Slaap B, Herdman M et al (2020) Which multi-attribute utility instruments are recommended for use in cost-utility analysis? A review of national health technology assessment (HTA) guidelines. Eur J Health Econ 21(8):12451257. https://doi.org/10.1007/s10198-020-01195-8

44. Rabin R, de Charro F (2001) EQ-SD: a measure of health status from the EuroQol group. Ann Med 33(5):337-343. https://doi. org/10.3109/07853890109002087

45. Janssen MF, Pickard AS, Golicki D et al (2013) Measurement properties of the EQ- 5D-5L compared to the EQ-5D-3L across eight patient groups: a multi-country study. Qual Life Res 22(7):1717-1727. https://doi.org/10.1007/s11136-012-0322-4

46. Kreimeier S, Greiner W (2019) EQ-5D-Y as a health-related quality of life instrument for children and adolescents: the instrument's characteristics, development, current use, and challenges of developing its value set. Value Health 22(1):31-37. https://doi.org/10.1016/j.jval.2018.11.001

47. Lipman SA, Reckers-Droog VT, Kreimeier S (2021) Think of the children: a discussion of the rationale for and implications of the perspective used for EQ-5D-Y health state valuation. Value Health 24(7):976-982. https://doi.org/10.1016/j.jval.2021.01. 011

48. Krig S, Åström M, Kulane A, Burström K (2021) Acceptability of the health-related quality of life instrument EQ-5D-Y-5L among patients in child and adolescent psychiatric inpatient care. Acta Paediatr 110(3):899-906. https://doi.org/10.1111/apa.15547

49. Zhou W, Shen A, Yang Z et al (2021) Patient-caregiver agreement and test-retest reliability of the EQ-5D-Y-3L and EQ-5D-Y$5 \mathrm{~L}$ in paediatric patients with haematological malignancies. Eur J Health Econ 22(7):1103-1113. https://doi.org/10.1007/ s10198-021-01309-w

50. Yang F, Devlin N, Luo N (2019) Impact of mapped EQ-5D utilities on cost- effectiveness analysis: in the case of dialysis treatments. Eur J Health Econ 20(1):99-105. https://doi.org/10.1007/ s10198-018-0987-x

51. Ravens-Sieberer U, Wille N, Badia X et al (2010) Feasibility, reliability, and validity of the EQ-5D-Y: results from a multinational study. Qual Life Res 19(6):887-897. https://doi.org/10.1007/ s11136-010-9649-X

52. Wu XY, Ohinmaa A, Johnson JA, Veugelers PJ (2014) Assessment of children's own health status using visual analogue scale and descriptive system of the EQ-5D-Y: linkage between two systems. Qual Life Res 23(2):393-402. https://doi.org/10.1007/ s11136-013-0479-5

53. Bergfors S, Åström M, Burström K, Egmar A-C (2015) Measuring health-related quality of life with the EQ-5D-Y instrument in children and adolescents with asthma. Acta Paediatr 104(2):167-173. https://doi.org/10.1111/apa.12863 
54. Mayoral K, Rajmil L, Murillo M et al (2019) Measurement properties of the online EuroQol-5D-youth instrument in children and adolescents with type 1 diabetes mellitus: questionnaire study. J Med Internet Res 21(11):e14947. https://doi.org/10.2196/14947

55. López-Bastida J, López-Siguero JP, Oliva-Moreno J et al (2019) Health-related quality of life in type 1 diabetes mellitus pediatric patients and their caregivers in Spain: an observational crosssectional study. Curr Med Res Opin 35(9):1589-1595. https:// doi.org/10.1080/03007995.2019.1605158

56. Murillo M, Bel J, Pérez J et al (2017) Health-related quality of life (HRQOL) and its associated factors in children with type 1 diabetes mellitus (T1DM). BMC Pediatr 17(1):16. https://doi.org/ 10.1186/s12887-017-0788-x

57. Scott D, Scott C, Jelsma J et al (2019) Validity and feasibility of the self-report EQ- 5D-Y as a generic health-related quality of life outcome measure in children and adolescents with juvenile idiopathic arthritis in western cape, South Africa. S Afr J Physiother 75(1):1335. https://doi.org/10.4102/sajp.v75i1.1335

58. Varni JW, Seid M, Rode CA (1999) The PedsQL: measurement model for the pediatric quality of life inventory. Med Care 37(2):126-139. https://doi.org/10.1097/00005650-19990 2000-00003

59. Varni JW, Seid M, Smith Knight T et al (2002) The PedsQL in pediatric rheumatology: reliability, validity, and responsiveness of the pediatric quality of life inventory generic core scales and rheumatology module. Arthritis Rheum 46(3):714-725. https:// doi.org/10.1002/art.10095

60. Varni JW, Seid M, Kurtin PS (2001) PedsQL 4.0: reliability and validity of the pediatric quality of life inventory version 4.0 generic core scales in healthy and patient populations. Med Care 39(8):800-812. https://doi.org/10.1097/00005650-20010 8000-00006

61. Chan KS, Mangione-Smith R, Burwinkle TM et al (2005) The PedsQL: reliability and validity of the short-form generic core scales and asthma module. Med Care 43(3):256-265. https:// doi.org/10.1097/00005650-200503000-00008

62. McDonald J, Cassedy A, Altaye M et al (2021) Comprehensive assessment of quality of life, functioning and mental health in children with juvenile idiopathic arthritis and non-infectious uveitis. Arthritis Care Res (Hoboken). https://doi.org/10.1002/ acr.24551.10.1002/acr.24551 (Online ahead of print)

63. Wu HH, Wu FQ, Li Y et al (2021) The quality of life in Chinese juvenile idiopathic arthritis patients: psychometric properties of the pediatric quality of life inventor generic core scales and rheumatology module. Health Qual Life Outcomes 19(1):37. https://doi.org/10.1186/s12955-021-01683-2

64. Seid M, Huang B, Niehaus S et al (2014) Determinants of health-related quality of life in children newly diagnosed with juvenile idiopathic arthritis: HRQOL determinants in newly diagnosed JIA. Arthritis Care Res (Hoboken) 66(2):263-269. https://doi.org/10.1002/acr.22117

65. Hersh A (2011) Measures of health-related quality of life in pediatric systemic lupus erythematosus: childhood health assessment questionnaire (C-HAQ), child health questionnaire (CHQ), pediatric quality of life inventory generic core module (PedsQL-GC), pediatric quality of life inventory rheumatology module (PedsQL-RM), and simple measure of impact of lupus erythematosus in youngsters (SMILEY). Arthritis Care Res (Hoboken) 63(S11):S446-S453. https://doi.org/10.1002/acr. 20559

66. Joffe NE, Lynch-Jordan A, Ting TV et al (2013) Utility of the PedsQL rheumatology module as an outcome measure in juvenile fibromyalgia: assessment of PedsQL in juvenile FM. Arthritis Care Res (Hoboken) 65(11):1820-1827. https://doi.org/10. 1002/acr.22045
67. Yount SE, Cella D, Blozis S (2019) PROMIS®: standardizing the patient voice in health psychology research and practice. Health Psychol 38(5):343-346. https://doi.org/10.1037/hea00 00741

68. Gruber-Baldini AL, Velozo C, Romero S, Shulman LM (2017) Validation of the PROMIS ${ }^{\circ}$ measures of self-efficacy for managing chronic conditions. Qual Life Res 26(7):1915-1924. https:// doi.org/10.1007/s11136-017-1527-3

69. Bevans M, Ross A, Cella D (2014) Patient-reported outcomes measurement information system (PROMIS): efficient, standardized tools to measure self-reported health and quality of life. Nurs Outlook 62(5):339-345. https://doi.org/10.1016/j.outlook.2014. 05.009

70. Evans JP, Smith A, Gibbons C et al (2018) The National institutes of health patient- reported outcomes measurement information system (PROMIS): a view from the UK. Patient Relat Outcome Meas 9:345-352. https://doi.org/10.2147/PROM.S141378

71. Forrest CB, Bevans KB, Pratiwadi R et al (2014) Development of the PROMIS ${ }^{\circledR}$ pediatric global health (PGH-7) measure. Qual Life Res 23(4):1221-1231. https://doi.org/10.1007/ s11136-013-0581-8

72. Forrest CB, Tucker CA, Ravens-Sieberer U et al (2016) Concurrent validity of the PROMIS ${ }^{\circledR}$ pediatric global health measure. Qual Life Res 25(3):739-751. https://doi.org/10.1007/ s11136-015-1111-7

73. Forrest CB, Zorc JJ, Moon J et al (2019) Evaluation of the PROMIS pediatric global health scale (PGH-7) in children with asthma. J Asthma 56(5):534-542. https://doi.org/10.1080/02770 903.2018.1471701

74. Holbein CE, Plevinsky J, Patel T et al (2021) Pediatric global health in children with very early-onset inflammatory bowel disease. J Pediatr Psychol 46(7):747-756. https://doi.org/10.1093/ jpepsy/jsab035

75. Iturralde E, Adams RN, Barley RC et al (2017) Implementation of depression screening and global health assessment in pediatric subspecialty clinics. J Adolesc Health 61(5):591-598. https://doi. org/10.1016/j.jadohealth.2017.05.030

76. Haas K, Martin A, Park KT (2017) Text message intervention (TEACH) improves quality of life and patient activation in celiac disease: a randomized clinical trial. J Pediatr 185:62-67.e2. https://doi.org/10.1016/j.jpeds.2017.02.062

77. Troost JP, Waldo A, Carlozzi NE et al (2020) The longitudinal relationship between patient-reported outcomes and clinical characteristics among patients with focal segmental glomerulosclerosis in the nephrotic syndrome study network. Clin Kidney J 13(4):597-606. https://doi.org/10.1093/ckj/sfz092

78. Gannotti ME, Law M, Bailes AF et al (2016) Comparative effectiveness research and children with cerebral palsy: identifying a conceptual framework and specifying measures. Pediatr Phys Ther 28(1):58-69. https://doi.org/10.1097/PEP.0000000000000203

79. Santoro SL, Campbell A, Cottrell C et al (2021) Piloting the use of global health measures in a down syndrome clinic. J Appl Res Intellect Disabil 34(4):1108-1117. https://doi.org/10.1111/jar. 12866

80. Luijten MAJ, van Muilekom MM, Teela L et al (2021) The impact of lockdown during the COVID-19 pandemic on mental and social health of children and adolescents. Qual Life Res 30(10):27952804. https://doi.org/10.1007/s11136-021-02861-x

81. Strisciuglio C, Martinelli M, Lu P et al (2021) Overall impact of COVID-19 outbreak in children with functional abdominal pain disorders: results from the first pandemic phase. J Pediatr Gastroenterol Nutr. https://doi.org/10.1097/MPG.0000000000003286 (Online ahead of print)

82. Cheng L, Kang Q, Wang Y, Hinds PS (2020) Determining the effectiveness of using patient-reported outcomes in pediatric 
clinical practices. J Pediatr Nurs 55:100-109. https://doi.org/10. 1016/j.pedn.2020.07.005

83. Janssens A, Thompson Coon J, Rogers M et al (2015) A systematic review of generic multidimensional patient-reported outcome measures for children, part I: descriptive characteristics. Value Health 18(2):315-333. https://doi.org/10.1016/j.jval.2014.12.006

84. Matza LS, Patrick DL, Riley AW et al (2013) Pediatric patientreported outcome instruments for research to support medical product labeling: report of the ISPOR PRO good research practices for the assessment of children and adolescents task force. Value Health 16(4):461-479. https://doi.org/10.1016/j.jval.2013. 04.004

85. Reeve BB, McFatrich M, Mack JW et al (2020) Validity and reliability of the pediatric patient-reported outcomes version of the common terminology criteria for adverse events. J Natl Cancer Inst 112(11):1143-1152. https://doi.org/10.1093/jnci/djaa016

86. Lundberg V, Eriksson C (2017) Health-related quality of life among Swedish children with juvenile idiopathic arthritis: parentchild discrepancies, gender differences and comparison with a European cohort. Pediatr Rheumatol Online J 15(1):26. https:// doi.org/10.1186/s12969-017-0153-5

87. Hall CA, Donza C, McGinn S et al (2019) Health-related quality of life in children with chronic illness compared to parents: a systematic review. Pediatr Phys Ther 31(4):315-322. https://doi. org/10.1097/PEP.0000000000000638

88. Matza LS, Swensen AR, Flood EM et al (2004) Assessment of health-related quality of life in children: a review of conceptual, methodological, and regulatory issues. Value Health 7(1):79-92. https://doi.org/10.1111/j.1524-4733.2004.71273.x

89. Hersh AO, Salimian PK, Weitzman ER (2016) Using patientreported outcome measures to capture the patient's voice in research and care of juvenile idiopathic arthritis. Rheum Dis Clin North Am 42(2):333-346. https://doi.org/10.1016/j.rdc.2016.01. 004

90. Bovis F, Consolaro A, Pistorio A et al (2018) Cross-cultural adaptation and psychometric evaluation of the juvenile arthritis multidimensional assessment report (JAMAR) in 54 languages across 52 countries: review of the general methodology. Rheumatol Int 38(Suppl 1):5-17. https://doi.org/10.1007/s00296-018-3944-1

Publisher's Note Springer Nature remains neutral with regard to jurisdictional claims in published maps and institutional affiliations. 